\title{
Nuevas estrategias retóricas en la sociedad de la neopublicidad
}

\section{New rhetorical strategies in the society of neoadvertising}

\author{
Jesús Bermejo Berros
}

Director de Lipsimedia Ad-Lab, Universidad de Valladolid

Fecha de recepción: 26 de octubre de 2012

Fecha de revisión: 23 de diciembre de 2012

Para citar este artículo: Bermejo Berros, J. (2013): Nuevas estrategias

retóricas en la sociedad de la neopublicidad, Icono 14, volumen 11 (1), pp. 99-124. doi: 10.7195/ri14.v11i1.528 


\section{Resumen}

El artículo presenta un nuevo tipo de estrategia retórica utilizada por la publicidad en la actualidad que está dando lugar a diferentes manifestaciones publicitarias, entre ellas la aparición de un nuevo tipo de publicidad, que hemos denominado neopublicidad. Esta nueva estrategia, que modifica los procedimientos retóricos seguidos hasta ahora por la publicidad clásica del siglo XX, se caracteriza por el enmascaramiento, que se sirve de recursos como el borrado de los marcadores de género, la hibridación y la fusión informativa. Este procedimiento tiene consecuencias sobre la manera en que el receptor responde al proceso persuasivo. Se ilustra la manifestación y finalidad de este fenómeno de transformación publicitaria en uno de los formatos publicitarios más clásico, el gráfico, donde hemos podido identificar tres tipos de neopublicidad: la publicidad integrada, el neopublireportaje y la publicidad autoreferencial. Estas nuevas estrategias son distintas a aquellas impulsadas en la sociedad de la postpublicidad, favorecidas éstas por las nuevas formas de comunicación resultantes de las nuevas tecnologías de la información y la comunicación, pero convergen con ellas en un marco social común donde la retórica publicitaria está evolucionando hacia nuevas formas de persuasión.

\section{Palabras clave}

Retórica - publicidad - persuasión - neopublicidad - postpublicidad - enmascaramiento

\section{Abstract}

This paper presents a new kind of rhetorical strategy used by advertising at present that is leading to different advertising manifestations, including the emergence of a new type of advertising, which we called neo-advertising. This new strategy, that modifies rhetorical procedures followed so far by the twentieth-century classic advertising, is characterized by masking. This strategy uses procedures as erasing gender markers, hybridization and informational fusion. This procedure has implications for how the receiver responds to the persuasive process. We show here some manifestations of this phenomenon and purposes of advertising transformation 
into one of the most classic advertising formats, print advertising, where we have identified three neo-advertising modalities: embedded ads, neoadvertorials and selfreferent ads. These new strategies are different from those promoted in the society of post-advertising, favored by these new forms of communication resulting from new information technologies and communication. However both converge on a common social framework where rhetoric advertising is evolving towards new forms of persuasion.

\section{Key Words}

Rhetoric - Advertising - Persuasion - New-advertising - Post-adverstising - Masking

\section{Introducción}

La retórica nació, desapareció durante numerosos siglos y reapareció con vigor durante el siglo XX. Las condiciones sociales y el sistema político de la (imperfecta) democracia griega del siglo $V$ a.C., favorecieron su aparición. Venía a responder a unas necesidades precisas en el sistema social de la época, manifestadas en tres ámbitos sociales. En la administración de justicia se impone la necesidad de buscar formas eficaces de argumentar en el proceso de acusación y defensa. La discusión en el senado para dirimir la conveniencia en las tomas de decisión en los asuntos de la polis dio lugar al discurso deliberativo. Finalmente, la búsqueda del bien decir en el elogio de personajes, ciudades, eventos, discursos fúnebres, trajo consigo la aparición del discurso retórico epidíptico.

Tras figuras como Cicerón y Quintiliano en Roma, la retórica desaparece durante las monarquías absolutas que reinan en el mundo occidental, desde el siglo II hasta la emergencia de las democracias modernas desde principios de siglo XX. En toda esa larga ausencia sólo uno de los componentes de la retórica, la elocutio, había subsistido, refugiada en las artes (Pujante, 2011). Recordemos que la retórica clásica es un procedimiento persuasivo compuesto de varios procesos sucesivos: inventio, dispositio, elocutio, memorización y acción. Como consecuencia de ese desgajamiento histórico de las partes de la retórica clásica, que habían llevado a la permanencia de la elocutio en un determinado tipo de texto artístico, una corriente de pensamiento durante el siglo XX (Grupo $\mu$, 1987) ha venido utilizando

DOI: ri14.v11i1.528 | ISSN: 1697-8293 | Año 2013 Volumen 11 N 01 | ICONO14 
la palabra retórica en el sentido de lo que propone la elocutio (adornar, contribuir al bien decir, el estilo, etc.) Desde otra perspectiva (Perelman y Ollbrechts-Tyteca, 1989; Toulmin, 2007), sin embargo, se ha entendido la retórica en el sentido de una teoría de la argumentación (más centrada en los procesos de la inventio y la dispositio). No obstante hemos de tener presente que ambas perspectivas corresponden a partes de un fenómeno de conjunto, tal y como lo entendía la retórica clásica y ambas están presentes y son necesarias en el discurso publicitario. La retórica es así un modo de acción e intercambio social, íntimamente ligado a los estados democráticos y los regímenes en libertad donde el contrato social no viene dado por la imposición sino por el intento de convencer a otro de lo bien fundado de una posición a partir del uso de argumentos (y no de la fuerza, la coerción 0 la propaganda, propias de regímenes absolutistas). La retórica es, en definitiva, el arte de persuadir en un acto de comunicación, de convencer al otro mediante recursos argumentativos (siendo un argumento todo aquello todo aquello que se dice en beneficio de una determinada posición) buscando que el destinatario modifique su percepción sobre el objeto del discurso acercándola a la posición deseada por el emisor.

La publicidad, que se despliega en los medios de comunicación de masas durante el siglo XX, será una sutil mezcla de los discursos epidíptico y deliberativo (del elogio y lo conveniente), en la que se utilizará un conjunto de estrategias persuasivas (Adam y Bonhomme, 2000; Bermejo, 2004; León, 2008), catorce en el caso de la publicidad gráfica como veremos más abajo (Bermejo, 2011). Ahora, a comienzos del siglo XXI, se observan cambios significativos en las estrategias publicitarias que ilustran la dinámica inherente al discurso retórico. Como un organismo vivo, la publicidad evoluciona y se adapta a los nuevos contextos culturales en los que despliega su acción. En el presente artículo analizamos la manifestación de una nueva estrategia retórica, el enmascaramiento, que está utilizando el discurso publicitario en la publicidad gráfica actual dando lugar a una nueva forma retórica que podemos denominar neopublicitaria. Ilustraremos sus manifestaciones y analizaremos su finalidad retórica. 


\section{La sociedad de la postpublicidad y la neopubli-}

\section{cidad}

Las cosas están cambiando en publicidad. Algunas voces afirman que hemos entrado en la era de la postpublicidad (Solana, 2010). Ello no significa, en modo alguno, que hayamos pasado a un escenario donde la publicidad queda atrás y deja de existir. La publicidad sigue estando presente, con igual vigor que hasta ahora. La postpublicidad, desde esta perspectiva, estaría caracterizada por la interacción, la conversación y el diálogo compartido (Solana, 2010). La persuasión unidireccional ejercida por la publicidad desde los medios de comunicación de masas a lo largo del siglo XX estaría dando paso a otras formas de comunicación y relación entre el anunciante y su target a persuadir. Esta visión da por hecho que la publicidad sigue estando ahí, llena de empuje pero con otras armas. Éstas serían el resultado de las herramientas que ha puesto a nuestra disposición la era digital. La comunicación one to one, la bidireccionalidad y multidireccionalidad de los mensajes a través de canales tan diversos como Internet o las nuevas formas de neomarketing (Bermejo, 2008). Sin embargo, si todas esas propuestas están presentes y modifican las modalidades de relación persuasiva entre las personas en el entorno publicitario, giran exclusivamente en torno al factor que emana del uso de las nuevas tecnologías. Estas están generando nuevos modos de relación favorecidos por el uso de esas nuevas herramientas.

Todos estaríamos de acuerdo en que la publicidad no ha muerto sino que está entrando en una nueva era (Bermejo, 2009). No habría algo después de la publicidad sino ella misma transfigurada. En ese sentido no hay un fenómeno post publicitario por lo que preferiremos, en nuestro caso, hablar de neopublicidad.

Sin negar, bien al contrario, la influencia del factor tecnológico que hace posible la comunicación bi y multidireccional, nuestra perspectiva aquí es bien diferente. Llamaremos la atención sobre la aparición en la actualidad de otro factor distinto que afecta al estatus mismo de la publicidad y su capacidad persuasiva en el contexto cultural actual. Del mismo modo que el entorno social existente en la Grecia clásica hizo aparecer los tres tipos de discurso persuasivo arriba indicados, en la época actual el contexto social está experimentando una transformación que nos está afectando, haciendo que cambien las estrategias persuasivas utilizadas 
por la publicidad. En torno a esa transformación presentaremos aquí algunas manifestaciones de un tipo concreto de publicidad, la gráfica, que ilustra el cambio profundo que está teniendo lugar en la retórica publicitaria del nuevo siglo. Estos cambios afectan, no tanto a la superficie, a las técnicas y herramientas utilizadas para persuadir, como al fondo, a las motivaciones y actitudes de los agentes implicados en el proceso persuasivo y a los procedimientos seguidos para inducir la respuesta persuasiva que comienza a manifestarse en algunas formas de publicidad.

Uno de los rasgos distintivos del discurso persuasivo es adaptarse al contexto de producción en aras de la eficacia. El discurso epidíptico, tal y como se practicaba en la Grecia clásica, no funcionaría hoy. La manera de construir la inventio, la dispositio o la elocutio ha cambiado. Los héroes clásicos sobre los que se vertían elogios eran guerreros y maestros, en la actualidad son cantantes o deportistas. La función mítica que cumplen unos y otros es la misma, lo que ha cambiado ha sido el contexto histórico-social, con todos los condicionantes que ello trae consigo. Entre ellos los modos de elogio han cambiado, por sólo citar un ejemplo. La retórica no es una herramienta de la que nos servimos para la persuasión sino una estrategia, y como toda estrategia, sus tácticas y caminos cambian para adaptarse a los nuevos tiempos.

En nuestro caso mostraremos que una parte de la publicidad se ha disfrazado de "no publicidad". Parece que "ahí no hay publicidad". Nada más lejos de la realidad. Lo que se busca en esta nueva forma de comunicación es contrarrestar la contraargumentación exponencial que han vivido los consumidores en relación a la publicidad en las últimas décadas. La saturación publicitaria y las derivas indeseables de la sociedad de consumo, que ha puesto a la publicidad, entre otros factores, como causa de algunos males, ha llevado a genera actitudes de rechazo hacia ella y como consecuencia al fenómeno de la evitación a la exposición a la publicidad que implica bajas tasas de atención y retención de los mensajes publicitarios clásicos. Ello ha impelido a los anunciantes a buscar nuevas formas de comunicación más eficaces. Las estrategias, como veremos más abajo, están cambiando.

\section{Estrategias argumentativas durante el siglo $\mathrm{XX}$}

Antes de hablar de las estrategias persuasivas que están apareciendo en la ac-

ICONO14 | Año 2013 Volumen 11 № 01 | ISSN: 1697-8293 | DOI: ri14.v11i1.528 
tualidad, a comienzos del siglo XXI, es necesario previamente recordar de forma breve las estrategias que se han utilizado en publicidad gráfica durante el siglo XX.

La estrategia genérica utilizada por la publicidad del siglo XX, que engloba a su vez otras más particulares, ha consistido en simular un proceso dialógico (Bajtin, 1991; Linell, 1998), es decir, si en todo diálogo en la vida cotidiana existe bidireccionalidad entre los interlocutores y participantes en el diálogo, la publicidad, inserta en medios de comunicación sólo puede dirigir mensajes unidireccionales y por tanto no puede establecer, de facto, comunicación bidireccional y por tanto diálogo real. Sin embargo ello no le ha impedido simular un diálogo con su público como si realmente hubiera bidireccionalidad. La dialogicidad construida por la publicidad es un proceso de argumentación en el que se despliega un conjunto de técnicas (conscientes en la publicidad) de legitimación de creencias y comportamientos. En este proceso, el enunciador busca influir, modificar o reforzar las creencias o los comportamientos (conscientes o inconscientes) de los targets a los que se dirige (Plantan, 1996).

Pero no basta con simular un diálogo. Éste es sólo el escenario donde se desplegará la estrategia argumentativa que buscará conectar con el receptor. Dependiendo de cuál sea la intencionalidad del mensaje (y de otras tomas de decisión que emanan del plan de marketing y objetivos publicitarios), se habrá procedido a construir un dispositivo retórico que maneje unas estrategias argumentativas susceptibles de persuadir al receptor. En esa argumentación dialógica el enunciador intentará conducir a su interlocutor a adoptar una posición mediante la presentación de argumentos que tienen por objetivo mostrar la validez o lo bien fundado de ese intento de influir sobre el destinatario (Oleron, 1983). En todo ese proceso, el producto o la marca, están en el centro del mensaje.

De manera resumida, se han utilizado dos tipos de estrategias argumentativas particulares. Unas se han venido a denominar de fuente y otras de mensaje.

\subsection{Las estrategias persuasivas centradas en la fuente}

Estas estrategias articulan el mensaje en torno a una fuente. Ésta, presente en el anuncio de manera explícita, canaliza el proceso dialógico con el receptor, asumiendo la responsabilidad de los argumentos utilizados. Las tres dimensiones de ésta que más se han utilizado en publicidad son la credibilidad; el atractivo y

DOI: ri14.v1 1i1.528 | ISSN: 1697-8293 | Año 2013 Volumen 11 Nº1 | ICONO14 
el poder.

Un mensaje que utiliza la credibilidad como argumento persuasivo alcanza su objetivo cuando el receptor interioriza el mensaje procedente de la fuente con una actitud de confianza pues atribuye credibilidad a esa fuente. Hay dos componentes de la fuente que pueden engendrar credibilidad:

(a) su experiencia y competencia: el mensaje tiene mayor impacto cuando proviene de una fuente percibida como superior en conocimientos, en instrucción, en inteligencia, en éxito profesional, en definitiva, cuando tiene una experiencia y competencia suficiente con el producto.y

(b) su imparcialidad: el receptor sólo otorga su confianza al contenido del mensaje si la fuente le parece objetiva, desinteresada y sin intención de manipular o engañar. Es percibida como objetiva aquella fuente que no parece privilegiar, intencional o involuntariamente, uno de los aspectos del problema a expensas del otro y que no despierta sospechas de modificar su discurso en función de lo que su público espera de ella. (Eagly, Wood y Chaiken, 1978). La fuente es percibida como desinteresada cuando la opinión que expresa no parece motivada por intereses personales.

En segundo lugar, un mensaje puede centrar su estrategia persuasiva utilizando una fuente atractiva. Cuando el receptor es sensible a esta propuesta es porque tiene lugar un proceso de identificación. La atracción que el receptor puede sentir por la fuente es de orden afectivo: esta atracción se expresa a través de una reacción emocional y un juicio de valor favorable.

Según la vía seguida por el receptor en la identificación con la fuente, pueden distinguirse tres tipos de mensajes atractivos: por prestigio de la fuente; por similitud con la fuente; por atractivo fisico de la fuente. En el primer caso, el prestigio atribuido a la fuente proviene fundamentalmente de los logros pasados de ésta (su reputación, su riqueza, etc.). Es el caso, por ejemplo, de personajes públicos de reconocido prestigio en sus campos profesionales que se ponen al frente de asociaciones no gubernamentales, de movimientos pacifistas, de actividades prosociales, etc. Cuando el atractivo de la fuente es por similitud se produce un proceso en el que el receptor percibe que sus creencias y actitudes son compartidas por la fuente (Berscheid, 1985) o que la fuente representa una clase social o grupo étnico preciso (Sears y Funk, 1991). Finalmente, la presentación de una fuente con atractivo físico puede generar identificación a través del mecanismo de

ICONO14 | Año 2013 Volumen 11 № 01 | ISSN: 1697-8293 | DOI: ri14.v11i1.528 
la seducción.

Por último, un tercer tipo de estrategia persuasiva se ha construido en torno al poder de la fuente. Este concepto designa la capacidad de la fuente para controlar los resultados que el receptor puede obtener, o dicho más directamente, para administrar recompensas y castigos. El impacto persuasivo a partir de este tipo de fuente sobre el receptor se denomina conformidad o condescendencia.

\subsection{Las estrategias persuasivas centradas en el mensaje}

Si en todo mensaje existe necesariamente una fuente, responsable del proceso de enunciación, las estrategias de mensaje se refieren al hecho de que el mensaje es construido dejando en segundo plano la fuente y centrándolo en algún tipo de contenido. El propósito de éste es ensalzar las ventajas y beneficios del producto y la marca. Se han podido identificar al menos ochos estrategias persuasivas capaces de producir efectos persuasivos:

(a) Logos: el mensaje privilegia la presentación de unos argumentos que apelan a la razón y la lógica: la conclusión se deduce forzosamente de las premisas. Un ejemplo de esta categoría, muy utilizado en el terreno de la publicidad, es dirigir al receptor sobre el reclamo publicitario, la oferta.

(b) Pathos: Compete al Pathos la argumentación que apela a las emociones y sentimientos. Son mensajes que se concentran en generar una reacción emocional del receptor trasladándole a una atmósfera placentera que intensifique su ego, su Pathos. Según McGuire "un llamamiento emocional argumenta en favor de una posición poniendo el acento sobre la deseabilidad de las consecuencias que se desprenderían de la aceptación de la posición evocada" (McGuire, 1969, p. 202).

(c) Ethos: argumentos que apelan a la autoridad de un texto, de una ley religiosa o moral, de una institución o bien de una persona investida con un mandato, de un personaje célebre; también competen a esta categoría los argumentos que utilizan el peso del número (i.e. compre la marca líder) y de la tradición (i.e. whisky destilado según la tradición).

(d) Apelaciones emocionales fuertes: Se trata de mensajes que están centrados en utilizar apelaciones emocionales fuertes tales como el miedo (i.e. campañas de la DGT), la injusticia (i.e. campaña contra la pobreza), o la desigualdad.

Inoculación o refutación: Para este fin el tipo de mensaje que se ha utilizado es

DOI: ri14.v11i1.528 | ISSN: 1697-8293 | Año 2013 Volumen 11 N 01 | ICONO14 
aquel que presenta primero (preexposición) contra-argumentos débiles y después refuta con argumentos favorables al producto. De esta forma se pretende inocular argumentos débiles (de la posición competidora) que no resistirían al empuje de los argumentos fuertes de la propia posición.

(e) Apoyo: Es aquel que insiste sobre los beneficios de la marca.

(f) Humor: No se presenta ninguna ventaja producto ni ningún beneficio consumidor explícito sino una situación en clave de humor que busca generar una reacción emocional positiva a asociar con la marca o producto.

(g) Participativas y de contacto: En ellas se hace una puesta en escena de un intercambio entre el mensaje y el receptor. Mediante esta función fática (en el sentido que le atribuye Román Jakobson) se genera participación del receptor, lo que conduce a la simulación de una comunicación bidireccional que propicia la empatía.

\section{Nuevas estrategias argumentativas al inicio del}

\section{siglo XXI}

La Publicidad clásica corresponde a aquel mensaje publicitario gráfico claramente diferenciado y delimitado en la publicación que lo acoge. Existen marcadores claros, tales como marcos o recuadros, que lo separan de otros mensajes de diferente naturaleza como artículos informativos, reportajes, etc. Además, el contacto regular de los lectores con los lenguajes publicitarios y códigos utilizados por los publicitarios en este tipo de publicidad hace que identifiquen con facilidad el género del texto al que se exponen. Con el desarrollo de la prensa en el siglo XIX y el nacimiento de las agencias de publicidad, la publicidad clásica ha imperado a lo largo de todo el siglo XX

Si la publicidad en el inicio del siglo XXI sigue utilizando las estrategias de fuente y mensaje enumeradas más arriba, lo característico es que las inserta en un proceso nuevo caracterizado por el enmascaramiento del mensaje publicitario en otros géneros. Ello tiene como objetivo evitar la contraargumentación del receptor, que es una barrera contra los argumentos recibidos, y facilitar de este modo el proceso persuasivo. La nueva publicitaria o neopublicidad, responde a una estrategia 
de "hacer publicidad como si no se hiciera publicidad".

Podemos hacer referencia, entre otras existentes ya hoy, a dos formas de neopublicidad que responden a la nueva estrategia de Dicho de otro modo, un rasgo de la neopublicidad es el enmascaramiento del género publicitario. El enmascaramiento se sirve de recursos como el borrado de los marcadores de género, la fusión informativa y la hibridación. Encuentra su espacio no sólo en los discursos informativos sino que la cultura del entretenimiento audiovisual es hoy un territorio cada vez más propicio a su presencia enmascarada. En el caso de la publicidad gráfica podemos distinguir tres tipos de neopublicidad.

\subsection{Neopublicidad integrada}

Se trata de publicidad que se incorpora a un texto de naturaleza informativa. No es infrecuente encontrarla en entrevistas a famosos y personajes públicos. A medida que van respondiendo a las preguntas del entrevistador, cuentan sus maneras de ser y actuar en su cotidianeidad. Ello incluye, bien la alusión espontánea a los productos y marcas que consume el propio entrevistado, bien porque se dice o se sugiere abiertamente el nombre de éstos desde otra voz personal o impersonal (sea la del entrevistador, la de la revista, ...). He aquí unos ejemplos de la revista Cosmopoliltan. En el ejemplo 1, se entrevista a la actriz Eva Longoria.

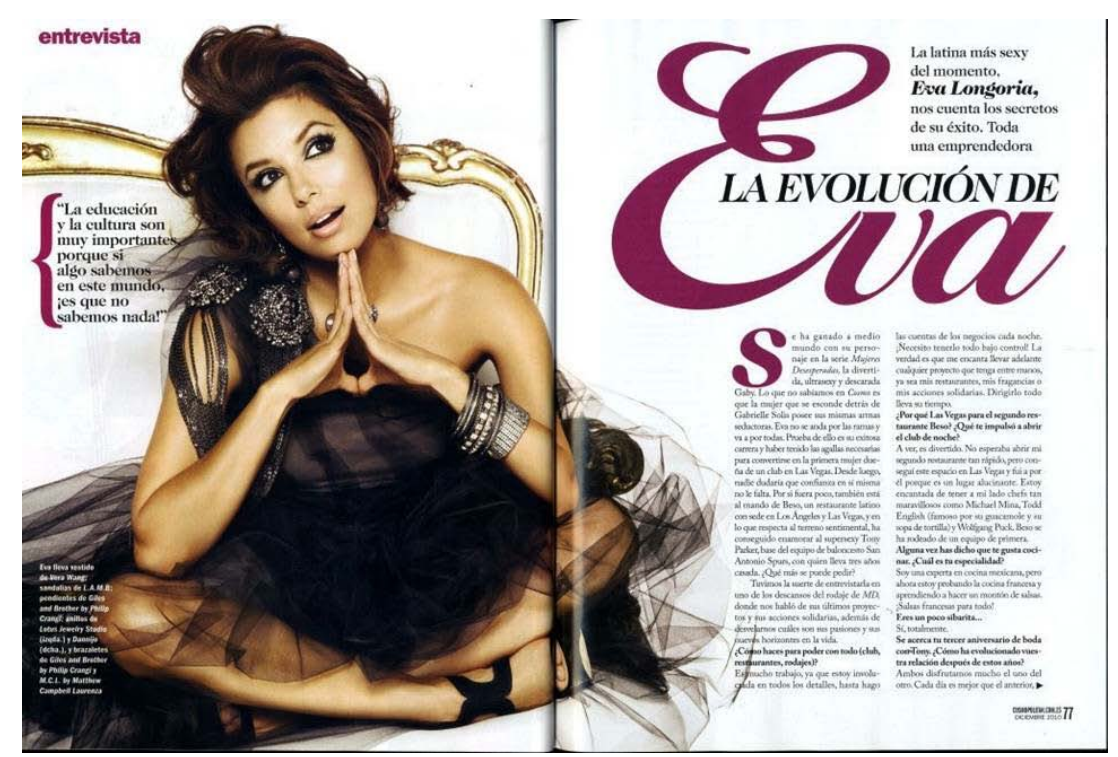

DOI: ri14.v11i1.528 | ISSN: 1697-8293 | Año 2013 Volumen 11 N 01 | ICONO14 


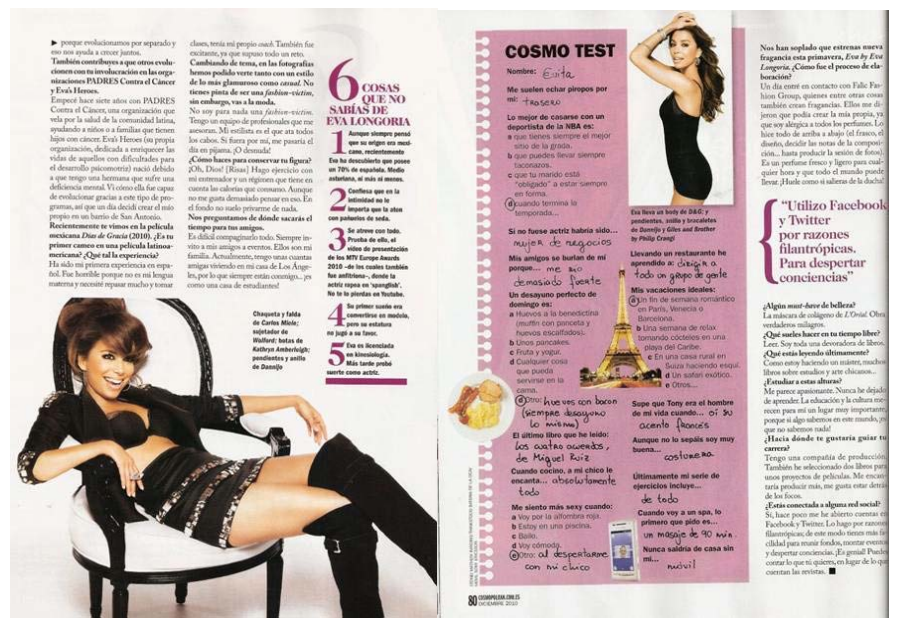

Gráfico 1: Neopublicidad integrada. Fuente: revista Cosmopolitan $n^{\circ} 243$

A lo largo del artículo habla de su vida y expresa sus gustos y preferencias. En ese contexto cita explícitamente algunas marcas de cosmética que ella utiliza y que le van muy bien. Dado el marco en que se produce la referencia publicitaria, el lector no reacciona de la misma forma a ella que si se tratase de una campaña convencional. Aquí nombrar la marca está justificado pues nos da a conocer una dimensión de la vida del personaje y de sus elecciones.

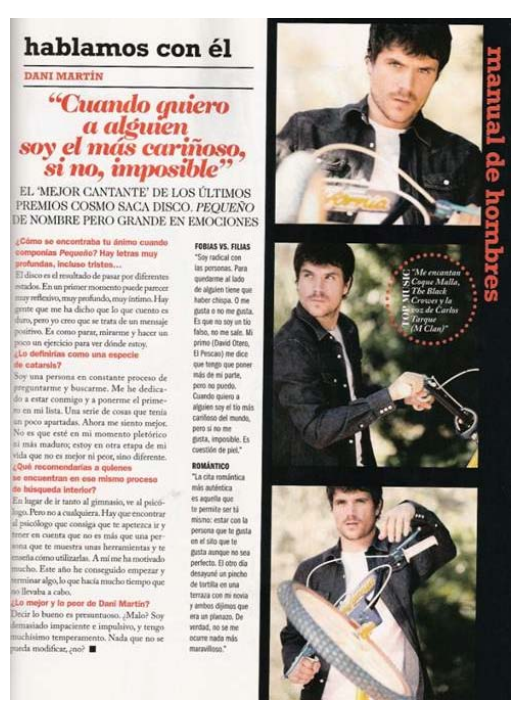

Gráfico 2: Neopublicidad integrada. Fuente: revista Cosmopolitan $n^{\circ} 243$ 
En el ejemplo 2, el cantante Dani Martín habla igualmente de sí mismo. A lo largo de la entrevista habla de su nuevo disco y también cita cantantes que le gustan. Estas alusiones, para alguien a quien guste este cantante, se convierten en prescripciones.

En el siguiente ejemplo 3 se introduce una variante.

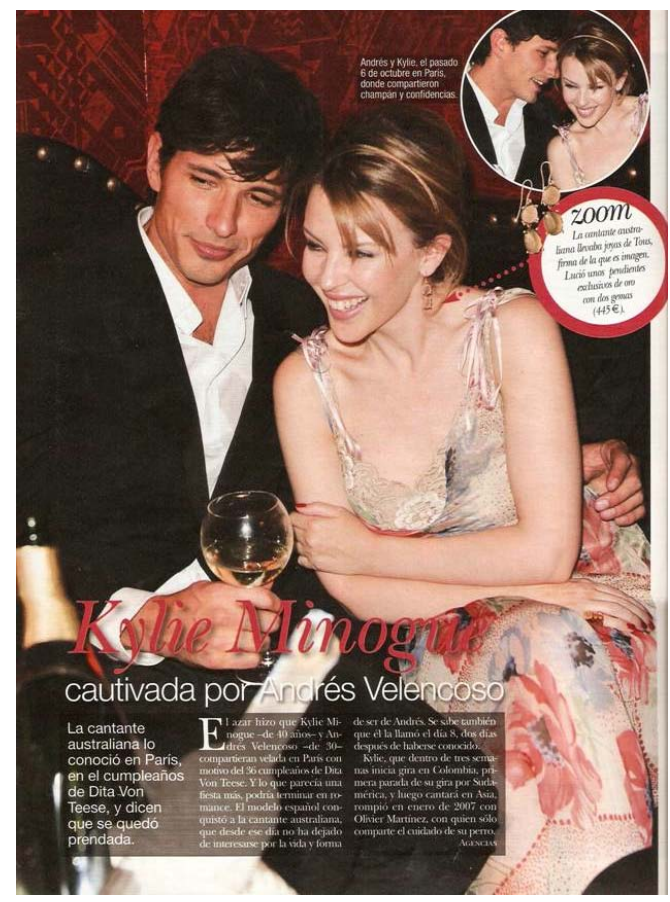

Gráfico 3: Neopublicidad integrada. Fuente: revista Cosmopolitan $n^{\circ} 243$

Tenemos un típico ejemplo de página de sociedad. En la imagen aparece la cantante australiana Kylie Minogne, acompañada de un hombre con quien supuestamente se especula mantendría una relación. Sin embargo, la novedad está en que esta "noticia de sociedad", característica de la prensa rosa, tiene integrada una apelación publicitaria. En la parte superior derecha de la imagen aparece un círculo en el que se dice que la cantante australiana lleva joyas de tal marca y de tal precio.

En definitiva, como vemos en estos ejemplos, no hay una puesta en escena en un contexto ficcional, como ocurre en la mayoría de la publicidad clásica, sino que esta puesta en escena corresponde al universo de la cotidianeidad de los per- 
sonajes. Aquí no se trata de que un personaje público se preste a participar en una campaña publicitaria, lo que ya ocurría en la publicidad clásica, sino que la publicidad se infiltra en la vida cotidiana de ese personaje y todo ello se hace público. Se publicita así la vida privada acompañada de marcas y alusiones publicitarias. Hay un proceso de fusión informativa en el sentido de que, en el interior de un mismo texto, sin código alguno que los delimite a ambos, tenemos información y publicidad de manera indisociable. Es fácil imaginar el efecto persuasivo de este proceder cuando existe una actitud previa positiva del receptor hacia el personaje.

\subsection{Neopublireportajes}

Los publireportajes ya existían en la publicidad clásica. En los neopublireportajes encontramos dos rasgos diferenciales con respecto a aquellos. El primero es que desaparece el encabezado del epígrafe en el que se podía leer la palabra «publireportaje» y que advertía al lector acerca del contenido. Hay por tanto un borrado del marcado de género.

El segundo rasgo, es que los neopublireportajes adquieren más un aspecto de verdadero reportaje informativo. Se hacen así, en no pocas ocasiones, más extensos que los clásicos publireportajes. A lo largo del neopublireportaje, el texto va sugiriendo productos y marcas con los que satisfacer aquello que va ofreciendo el texto (por ejemplo, maneras concretas de alojarse en tal o tal viaje; productos de cuidado del cuerpo para tratar tal o tal inconveniencia del sol;...). Estas alusiones a productos o servicios se hacen dentro del texto sin ocupar espacios separados al mismo, en recuadros aparte. El neopublireportaje es construido así a partir de un interrogante al que el artículo va a ir dando respuestas y explicaciones. A lo largo del desarrollo del texto se van sugiriendo productos y marcas a modo de meras sugerencias para resolver el problema suscitado. Por ejemplo, en el ejemplo 4 se enuncia la temática "Sexy \& Feliz en Navidad". A lo largo del texto (que ocupa en este caso 31 páginas de las que el ejemplo recoge la primera) se sugieren formas de vestir durante esas fiestas de manera concreta, es decir, mostrando ejemplos de marcas concretas en contexto concretos.

ICONO14 | Año 2013 Volumen 11 № 01 | ISSN: 1697-8293 | DOI: ri14.v11i1.528 


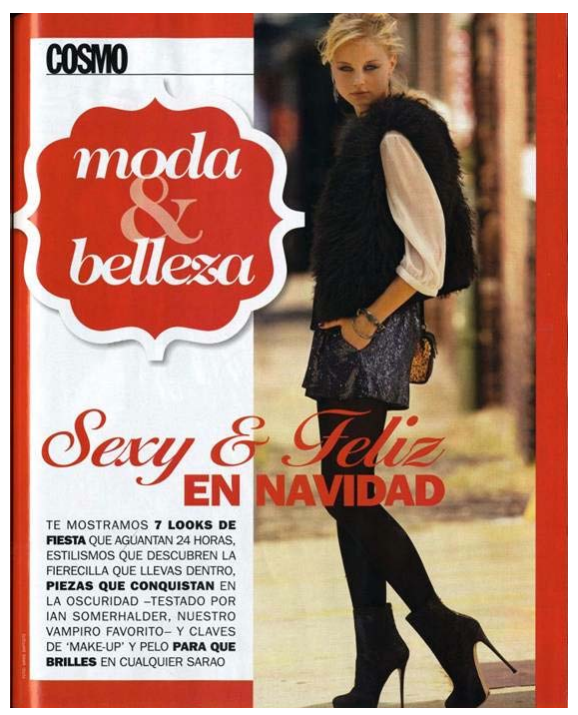

Gráfico 4: Neopublireportaje. Fuente: revista Cosmopolitan no 243

Los ejemplos 5 y 6 muestran otras dos temáticas propuestas por dos neopublireportajes. En el ejemplo 5 te van a sugerir maneras de resolver un problema que afecta al cuidado de tu piel en invierno. En el ejemplo 6 se sugieren formas de atajar la caída del cabello.

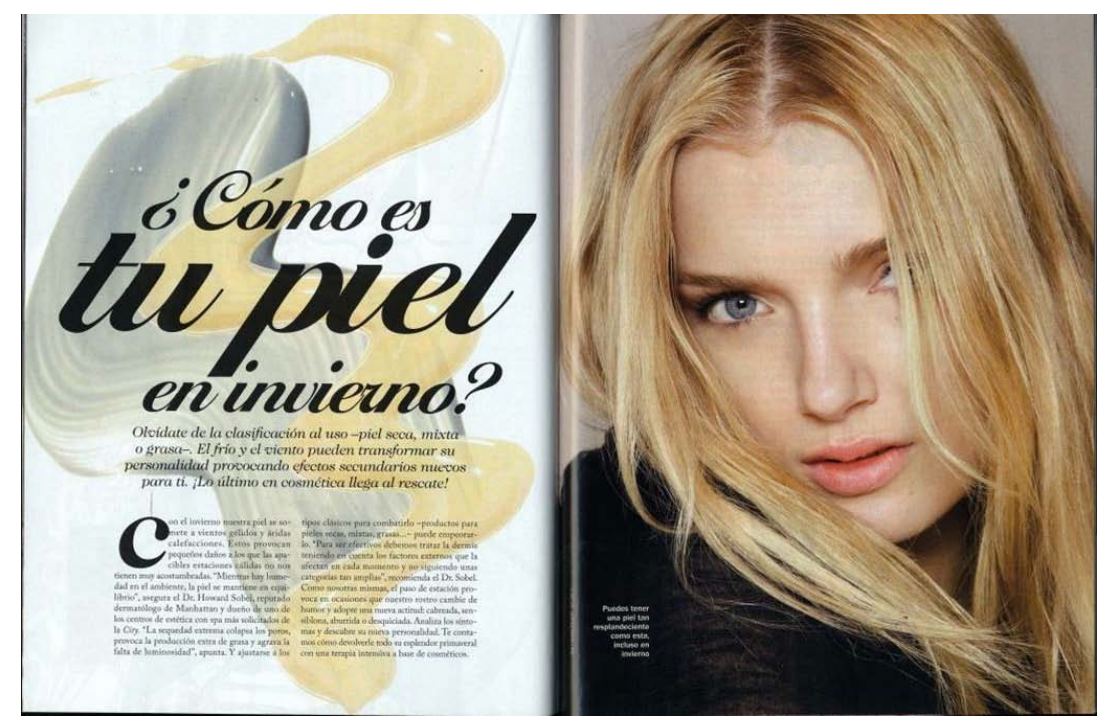

Gráfico 5: Neopublireportaje. Fuente: revista Cosmopolitan $n^{\circ} 243$ 


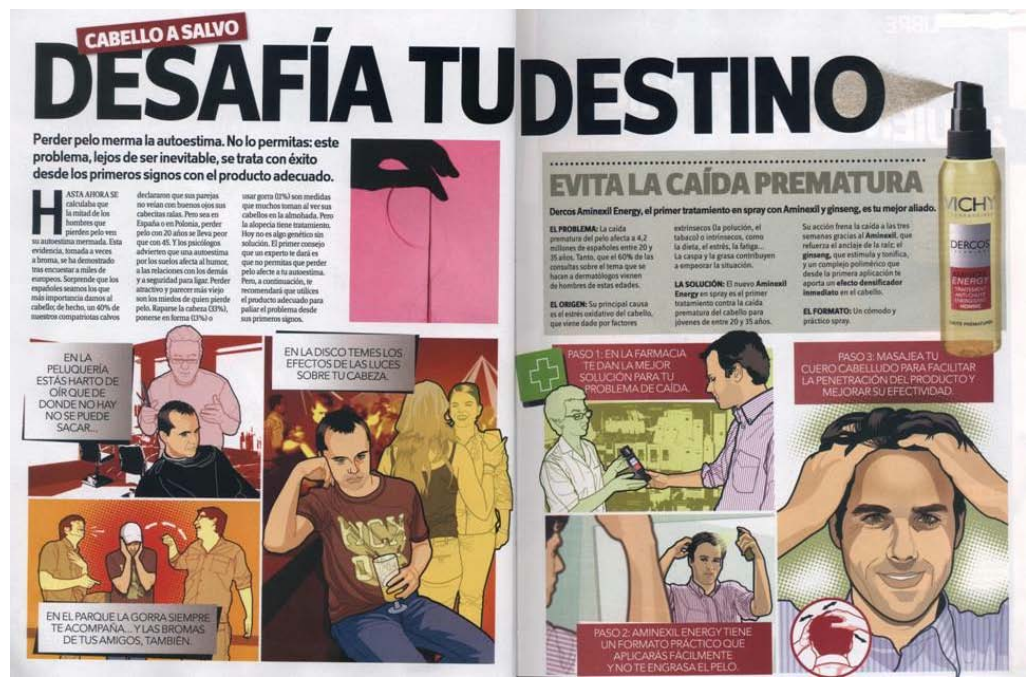

Gráfico 6: Neopublireportaje. Fuente: revista Cosmopolitan $n^{0} 243$

En el último ejemplo, $n^{0} 7$, el discurso no es presentado a partir de una interrogante referida a un problema sino que puede aparecer como un texto descriptivo en el que se informa acerca de un tema. Se da información sobre los caminos de ronda en una determinada región. Se da indicación de lugares que visitar, gastronomía del lugar, etc. Naturalmente el recorrido es acompañado de referencias explicitas publicitarias a restaurantes y hoteles precisos. Por tanto vemos aquí nuevamente la fusión informativa de los géneros informativo y publicitario.

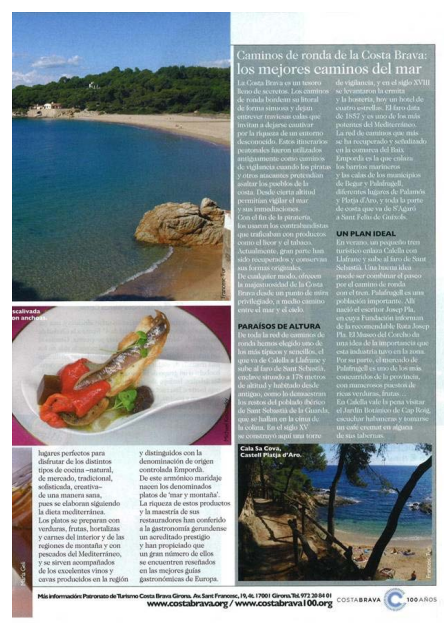

Gráfico 7: Neopublireportaje. Fuente: revista Cosmopolitan $n^{\circ} 243$

ICONO14 | Año 2013 Volumen 11 № 01 | ISSN: 1697-8293 | DOI: ri14.v11i1.528 
Como ilustran estos ejemplos, el neopublireportaje pone en el centro del texto el problema a resolver, dejando en un último plano, que aparecerá en el momento preciso de buscar soluciones, la sugerencia publicitaria. Si recordamos, en la publicidad clásica, el proceder es el inverso pues lo primero que aparece es el producto y la marca. Todo gira en torno a ellos. El problema era suscitado por la promesa publicitaria que venía a sugerir la resolución de aquel por el uso del producto publicitado.

\subsection{Mensajes autoreferenciales}

Al igual que en el caso anterior, aquí se borran aquellos códigos que permiten al lector identificar que el texto está haciendo un acto de promoción o de autopromoción.

En la publicidad clásica, como en la promoción del ejemplo $n^{0} 8$, se hacía referencia clara a un mensaje de promoción del producto/marca. En este ejemplo al hecho de que el nuevo número de la revista ya está a la venta. Todos los códigos del anuncio participan de este propósito discursivo.

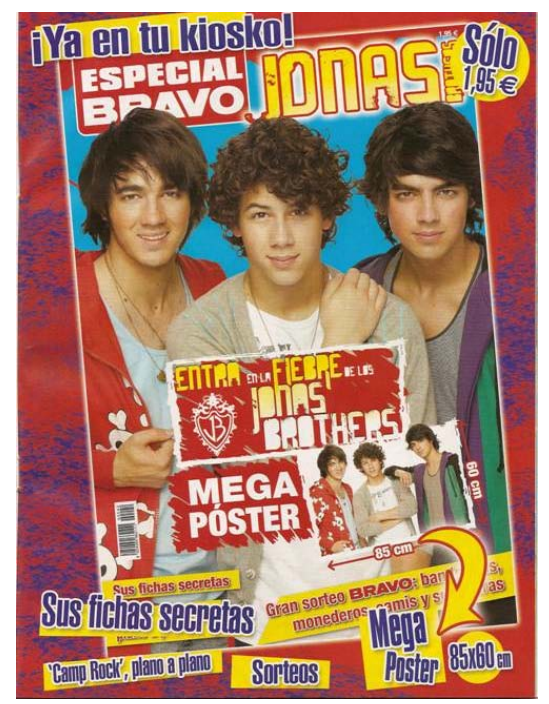

Gráfico 8: Ejemplo de autopromoción. Fuente: revista Cosmopolitan $n^{\circ} 243$

Sin embargo, en los nuevos mensajes autoreferenciales el acto de promoción 0 autopromoción se camufla en el interior de un mensaje de otra naturaleza. Como ilustra el ejemplo 9, nos presentan un reportaje sobre la fiesta de Cosmopolitan 
que ha tenido lugar y a la que han asistido numerosas personas conocidas. Se acompañan imágenes de éstas y el texto parece un reportaje de sociedad más, como los que podemos encontrar en la prensa people. Sin embargo, y ahí está la sutil presencia publicitaria, a lo largo de las páginas del reportaje vemos en numerosas ocasiones el logosímbolo de la marca Cosmopolitan (acompañada además de otras marcas para las que se hace publicidad). Hay por tanto una promoción de la marca pero hecha de manera velada, indirecta.
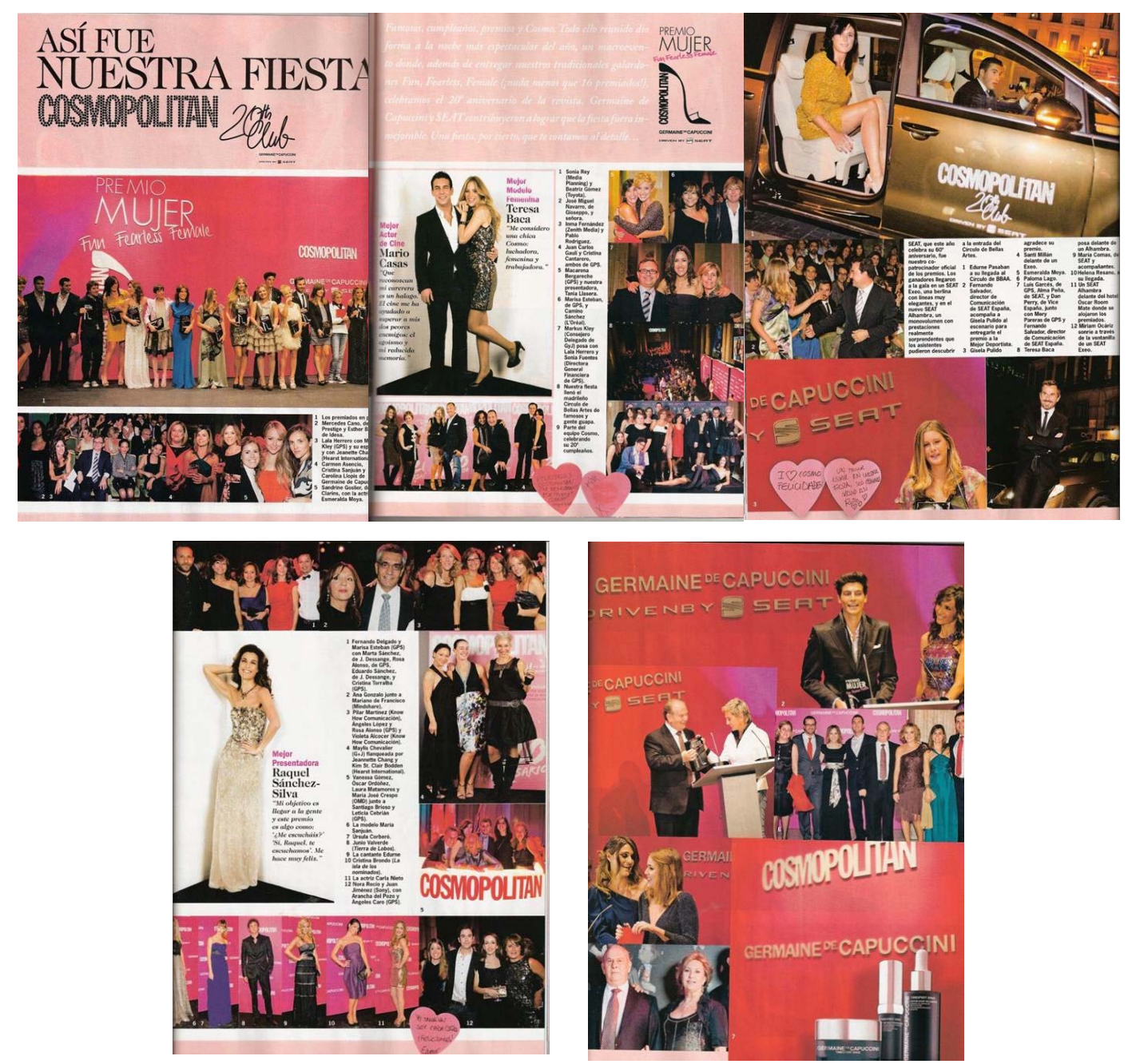

Gráfico 9: Publicidad autorreferencial. Fuente: revista Cosmopolitan $n^{\circ} 243$ 


\section{Extensión y efectos de la neopublicidad}

A partir de la constatación anterior, según la cual hemos podido detectar la existencia de nuevas estrategias retóricas, se plantean dos cuestiones interrelacionadas. Por un lado cuál es el alcance actual de esta nueva forma de publicidad $y$, en segundo lugar, de interés para la teoría retórica de la publicidad, cuáles son los efectos sobre el receptor. Nos referiremos a ellas brevemente aquí.

\subsection{La extensión de la neopublicidad gráfica}

En un estudio previo, habíamos seleccionado en el mercado español de prensa, el conjunto de publicaciones impresas que insertaban publicidad y que cualquier consumidor podía adquirir en un período preciso que se repite cíclicamente (Bermejo, 2011). Había hasta un total de 23 categorías de publicaciones que incluían todo el espectro de temáticas que pueden interesar a los compradores de medios impresos (por ejemplo, entre esas 23 categorías, había revistas de Arte y diseño; Juventud; Hogar y Confección; Automoción; Televisión; vinos; música; salud y cuidado personal; historia; sociedad; erotismo; humor; formación (guitarra, etc.); campo; divulgación científica; moda; animales; viajes; actualidad; economía; cine; bricolaje; diarios de información general y deportivos). El resultado final de la búsqueda arrojó un total de 232 publicaciones, distribuidas en las 23 categorías anteriores, que insertaban un total de 7.771 anuncios. El análisis de este corpus puso de manifiesto que la neopublicidad, tal y como la hemos caracterizado más arriba, representa ya el 23,5\% del total de la publicidad gráfica (Autorreferencial $10,2 \%$, Neopublireportaje 7,7\%, Integrada 5,6\%). Se trata, por tanto, de un fenómeno cuya extensión es significativa en el contexto publicitario gráfico actual.

\subsection{La influencia de la neopublicidad}

La persuasión publicitaria tiene una finalidad de eficacia. Es en la reacción del receptor donde podemos encontrar la respuesta a la interrogante de saber si estas nuevas estrategias, que como vemos no utilizan necesariamente las herramientas de las nuevas tecnologías sino la de transfigurar la intencionalidad del mensaje, 
consiguen o no trasladar al receptor su propósito retórico (captar su atención), condición necesaria para comunicar con él. Para indagar esta cuestión se investigó, en un segundo estudio (Bermejo, Frutos y Couderchon, 2011), el grado en que los lectores de prensa, revistas y publicaciones impresas, eran capaces de identificar en sus páginas la presencia de este tipo de neopublicidad. Para ello se procedió a utilizar una revista concreta, Cosmopolitan. Se trata de una revista con muchas páginas que incluye tanto publicidad clásica como los tres tipos de neopublicidad, arriba descritos. Participaron en la investigación 247 estudiantes universitarios del último curso de la licenciatura de Publicidad y RRPP. Se trataba así de seleccionar un grupo de receptores expertos en la medida en que están acostumbrados, dado su proceso de formación universitaria, a ser expuestos a mensajes publicitarios y a analizarlos de diversos modos. Esto hacía de este grupo un tipo de lector experto en comparación con cualquier otro lector no experto, es decir, no acostumbrado a escudriñar la publicidad. Para realizar la prueba cada sujeto acudía al Laboratorio LipsiMedia $^{2}$ en la Universidad de Valladolid, donde se instalaba en un puesto de ordenador (que estaba dotado de un software SuperLab 4.1. configurado para registrar las respuestas del sujeto). La consigna que se le daba era que a continuación iría viendo en el monitor una a una las páginas del número 243 de la revista Cosmopólitan (260 páginas). En la consigna se le precisaba que lo que tenía que ir indicando era si había o no publicidad en cada una de las páginas que iría viendo. Si su respuesta era afirmativa tenía que apretar la tecla $S$ en el teclado del ordenador y en caso negativo la tecla $\mathrm{N}$. Al realizar una de estas dos acciones el dispositivo hacía que se pasase a una nueva pantalla donde aparecía una nueva página de la revista a la que tenía que responder igualmente de manera afirmativa o negativa, y así sucesivamente. En la consigna se le señalaba además que se tomarían en cuenta dos cosas: si su respuesta era correcta o no y también el tiempo que había tardado en responder. Ambas respuestas eran registradas por el dispositivo instalado en el ordenador (en el caso del RT, Tiempo de Reacción, se medía el tiempo transcurrido desde el momento de presentación del anuncio en pantalla hasta la respuesta dada en el teclado). Por tanto el sujeto era invitado a hacer la prueba de manera correcta y al mismo tiempo lo más rápido posible.

Dado el grado de especialización de los sujetos, en esta situación experimental, cabía esperar que este grupo de lectores expertos no tuvieran gran dificultad para identificar la publicidad en la revista, fuera clásica o neopublicidad. Sin embar- 
go, sus respuestas arrojaron unos resultados distintos e interesantes para los 224 estímulos publicitarios insertos en la revista, a los que fueron expuestos los sujetos a lo largo de la prueba. Mientras que la publicidad clásica era correctamente identificada en un $94,2 \%$ del total de anuncios, la neopublicidad sólo lo era en un $53,1 \%$ (Autoreferencial 59,2\%, Neopublireportaje 51,7\% e Integrada 48,6\%). Estas diferencias entre los dos grandes tipos de publicidad, clásica y neopublicidad, eran estadísticamente significativas (Bermejo, Frutos y Couderchon, 2011). Por tanto, mientras nuestros lectores, expertos en publicidad, no habían tenido dificultad alguna para localizar la publicidad clásica, sólo habían sido capaces de hacerlo en la mitad de los estímulos neopublicitarios a los que habían sido expuestos. Ello tenía algunas consecuencias importantes, cuatro de la cuales discutiremos a continuación.

\section{Discusión y conclusión}

Los resultados de la investigación que hemos llevado a cabo suscitan la discusión en relación a algunas cuestiones. La primera tiene que ver con nuestra respuesta a los intentos persuasivos de la publicidad. Cuando el sujeto es confrontado a la publicidad clásica, la identificación de los códigos culturales, ligados a este tipo de discurso, le permite adscribir el mensaje al género publicitario $\mathrm{y}$, a partir de ese instante, puede activar procesos de contraargumentación, como ocurre hoy en no pocas ocasiones cuando la gente sabe que está ante un texto publicitario. Una de las consecuencias de este proceso es que las posibilidades de persuasión disminuyen sustancialmente. Por el contrario, cuando el sujeto lee un texto y no identifica en él un mensaje publicitario no tiende a activar procesos de contraargumentación. En este caso, las posibilidades de persuasión aumentan al no encontrarse con la barrera de los argumentos contrarios, activable por el sujeto. Esta ocultación o enmascaramiento de la publicidad, para evitar contraargumentación en la neopublicidad, crea así las condiciones de su mayor eficacia.

En segundo lugar, dado que el sujeto no alcanza en muchos casos a identificar la neopublicidad en un medio de comunicación impreso, como acabamos de ver, puede llegar a tener la impresión de que la publicidad "ya no está ahí", al menos en ese medio de comunicación gráfico. La saturación publicitaria en los media,

DOI: ri14.v11i1.528 | ISSN: 1697-8293 | Año 2013 Volumen 11 Nº1 | ICONO14 
uno de los factores del hastío y actitudes negativas de los consumidores hacia la publicidad, parecería así disminuir su presencia y por tanto su presión sobre el receptor. Ello trae consigo un grado añadido de relajamiento en la vigilancia hacia la detección de publicidad y, por tanto, una disminución de su disposición a activar actitudes de contraargumentación.

En tercer lugar, si la publicidad del siglo XX se ha caracterizado por utilizar estrategias argumentativas centradas en la fuente y en el mensaje, la neopublicidad del XXI profundiza en los procesos de dialogicidad. La estrategia ya no consiste en servirse de una fuente dotada de credibilidad o prestigio para que haga de mediador entre el anunciante y el lector. Tampoco se privilegian estrategias de mensaje que ensalcen el producto o la marca. Ahora, en la neopublicidad, se establece una relación más directa entre el enunciador y el lector (yo-tú), en torno a un topoi de interés común. En ese proceso de comunicación, el producto o la marca, verdadero eje del anuncio del siglo XX, pasa a un segundo plano, más solapado, aunque no menos presente. De este modo, si en la publicidad clásica, las promesas de la marca y el producto son el eje central de la comunicación, en la neopublicidad éstas se desplazan, ocupando su lugar nuclear un tema de interés común entre el destinador y el destinatario, en la medida en que la información que aporta el primero interesa al segundo. La simulación del diálogo de la publicidad clásica ha dado paso a un encuentro dialógico en torno a un contenido que atrae al lector.

En cuarto lugar, la nueva estrategia retórica de la neopublicidad conduce a la publicidad a argumentar en un contexto diferente al utilizado hasta ahora. Ello hará que ya no tenga tanta relevancia el eje dicotómico hegemónico en la publicidad del siglo XX, describiendo ésta en términos bien racionales bien emocionales (Bernstein, 1974, Simpson, 2001). Por un lado una publicidad racional en la que predominaba una argumentación mediante la puesta en escena de la demostración de las ventajas del producto, del logos. Por otro, una publicidad denominada emocional, dirigida a dar forma a nuestros sueños, a destacar los beneficios simbólicos sobre el imaginario del receptor (Scott y otros 2001; Gobé, 2005; Espantaleón, 2006; López, 2006). Si la publicidad del siglo XX es más directa, dirigiéndose abiertamente al receptor, mediante el logos o el pathos (Bermejo, 2011), la publicidad que se apunta en el siglo XXI es más indirecta, se oculta y diluye en otras formas de discurso para, a través de este procedimiento, servirse de las actitudes positivas hacia los contenidos de éstos y asociarlas a las del producto/marca. La

ICONO14 | Año 2013 Volumen 11 № 01 | ISSN: 1697-8293 | DOI: ri14.v11i1.528 
ruta de persuasión estaría así cambiando para seguir siendo eficaz. Durante el siglo XX la publicidad utilizó los medios de comunicación a modo de vehículos para llevar sus mensajes a los públicos. En los últimos años, la publicidad clásica ha seguido ahondado en sus propuestas emocionales que apelaban a un "mundo feliz" en contraste con la realidad cotidiana actual cada vez más atenazada por la crisis económica. Este doble mundo, de un lado el imaginario del deseo representado por la publicidad, y de otro, la realidad cotidiana llena de dificultades para encontrar trabajo y llegar a fin de mes. Sin embargo, haciendo caso omiso de ello, la publicidad ha seguido haciendo sus propuestas consumistas como si la sociedad continuase en el estado en que se encontraba hace varias décadas, a mediados del siglo XX, durante la expansión consumista de las sociedades industrializadas. Las cosas han cambiado hoy, en el siglo XXI, por lo que la prolongación de la estrategia de seguir construyendo mundos de deseo de consumo parece abocada a chocar con una realidad llena de dificultades materiales para, si quiera, aproximarse a la satisfacción de esos deseos propuestos desde los medios de comunicación. El necesario vínculo entre ambos mundos es ya demasiado lejano para generar verosimilitud, aun cuando sólo fuera de forma simbólica y fantasmada en el deseo. Estas dos realidades, la del mundo posible de la publicidad y la del mundo de la realidad cotidiana, cada vez más divergentes entre sí, puede conducir a romper sus frágiles vínculos mantenidos a duras penas hasta ahora. En parte como consecuencia de la toma de conciencia de esta dificultad de poder establecer una comunicación efectiva entre el anunciante y su target, la publicidad está buscando en la actualidad otras vías retóricas. A comienzos del siglo XXI la publicidad se está transfigurando, dando la impresión que abandona esos media. Pero sigue estando ahí, ahora fagocitando otros discursos de género diferente. No se trata de la mitificada publicidad subliminal pues es otra forma de publicidad, distinta a la neopublicitaria. El poder de ésta consiste en crear vínculos asociados a personajes por los que se interesa el lector (como el ejemplo en el que leemos una entrevista a un actor o cantante por el que nos interesamos), en participar en la respuesta a temáticas que preocupan al consumidor y para las que busca respuestas (como en el ejemplo de alguien que busca ideas para quedar bien en una fiesta, resolver su incipiente caída de cabello o encontrar lugares turísticos interesantes). El producto y la marca aparecen entonces ahí, de manera solapada, para acudir en respuesta a sus preocupaciones. El mecanismo psicológico es pues otro. Ya no se trata de convencer con argumentos

DOI: ri14.v11i1.528 | ISSN: 1697-8293 | Año 2013 Volumen 11 N 01 | ICONO14 
racionales al consumidor o transportarle simbólicamente a mundos posibles deseados (como en la publicidad clásica) sino de adherir el discurso publicitario, y el intento preciso en cada caso de alcanzar la aceptación del receptor de la posición sugerida por el mensaje, a los topoi y a los mitos a los que se aferran los públicos en nuestras sociedades contemporáneas tales como, por ejemplo, los personajes y héroes de hoy que admiramos y con los que nos identificamos, el culto al cuerpo, nuestro emergente acercamiento a la ecología, entre otras necesidades (Bermejo, 2007).

Hemos visto en el presente trabajo una de las manifestaciones de esa nueva retórica publicitaria, en soporte impreso. Otros síntomas, en los que no entraremos aquí, nos indican que las nuevas estrategias retóricas de la neopublicidad se están extendiendo también a otros soportes y formatos de la sociedad de la postpublicidad. Las nuevas tecnologías, capaces de crear lazos bidireccionales con el receptor, dan un paso más hacia la puesta en escena simulada de la dialogicidad, y por tanto de la relación comunicacional entre anunciante y target. La neopublicidad es otra de las manifestaciones que muestran el paso progresivo en la actualidad de las tradicionales estrategias push, características de la publicidad clásica, hacia estrategias pull. La cultura del entretenimiento, muy vinculada a esos entornos audiovisuales multimedia facilita la penetración de la neopublicidad. En ese contexto la estrategia de ésta, tal y como la hemos definido aquí, es susceptible de extenderse a todos esos nuevos medios de relación que se tratará de escudriñar para entender y comprender los mecanismos actualizados de la retórica publicitaria.

\section{Notas}

[1] Esta investigación forma parte del proyecto de investigación del plan nacional CS0200912568-C03-02

[2] LipsiMedia (Laboratorio de Investigación Publicitaria y Psicología de los Media, ubicado en la Facultad de Ciencias Sociales, Jurídicas y de la Comunicación de la Universidad de Valladolid) lispimedia@gmail.com

ICONO14 | Año 2013 Volumen 11 № 01 | ISSN: 1697-8293 | DOI: ri14.v11i1.528 


\section{Referencias}

Adam, J. M. y Bonhomme, M. (2000). La argumentación publicitaria. Retórica del elogio y de la persuasión. Madrid: Cátedra.

Bajtin, M. (1991). Teoría y estética de la novela. Madrid: Taurus.

Bermejo Berros, J. (2004). Los límites de la persuasión: entre la seducción y la propaganda", en Eguizábal, R. (Coord.). La Comunicación Publicitaria. Antecedentes y tendencias en la Sociedad de la Información y el Conocimiento.

Sevilla: Comunicación Social. Ediciones y publicaciones.

- (2007). Teoría del Hexágono de Apelaciones Publicitarias y de Necesidades

Emergentes. Pensar la Publicidad. Revista Internacional de Investigaciones

Publicitarias, Vol. 1, n 1, 99-131

- (2008). El receptor publicitario del siglo XXI en el marco de la interactividad:

entre el consumer y el prosumer. En Marta Pacheco Rueda (Coord.) La

publicidad en el contexto digital. Viejos retos y nuevas oportunidades. Sevilla:

Comunicación Social. Ediciones y Publicaciones.

- (2009). Sobre la muerte y resurrección de la publicidad. Pensar la Publicidad.

Revista Internacional de Investigaciones Publicitarias, Vol. 3, no 2, 9-16

- (2011). Estrategias persuasivas de la comunicación publicitaria en el marco del

sistema publicitario gráfico español, Sphera pública, nº 11, 21-41.

Bermejo, J., De Frutos, B. Y Couderchon, P. (2011). The perception of print

advertising in the new strategies of hybridisation of genres. Paper: 10th

International Conference on Research in Advertising (ICORIA). Berlín, 23-

25 de junio 2011. Europa-Universität Viadrina Frankurt (Oder) y Bergische

Universität Wuppertal.

Bernstein, D. (1974). Creative advertising, London: Longman.

Berscheid, E. (1985). Interpersonal attraction. In G. Lindzey\&E. Aronson (Eds.),

The handbook of social psychology (Vol. 2., pp. 413-484). New York: Random House

Eagly, A. H., Wood, W., \& Chaiken, S. (1978). Causal inferences about

communicators and their effect on opinion change. Journal of Personality and Social Psychology, 36, 424-435.

Espantaleón, R. (2006). Humanizar las marcas o la moda emocional, Anuncios, $n^{0} 1154,26$ de junio a 2 de julio. 
Gobé, M. (2001). Branding emocional: el Nuevo paradigma para conectar las marcas emocionalmente con las personas. Barcelona: Divine Egg Publicaciones.

Grupo $\mu$ (1987). Retórica general, Barcelona: Ediciones Paidós Comunicación. León, J. L. (2008). Persuasión pública. Bilbao: Servicio Editorial de la UPF. Linell, P. (1998). Approaching dialogue. Talk, interaction and contexts in dialogical perspective. Amsterdam y Philadelphia: John Benjamins.

López Vázquez, B. (2007). Publicidad emocional. Estrategias creativas. Madrid: Esic.

McGuire, W. J. (1969). The nature of attitudes and attitude change. En G. Lindzey y E. Aronson (Eds.), Handbook of Social Psychology, Vol. 3, 136-314. Reading, MA: Adison-Wesley.

Oleron, P. (1983). L'argumentation. Paris: PUF

Perelman, C. y Olbrechts-Tyteca, L. (1989). Tratado de la Argumentación. La Nueva Retórica. Madrid: Ed. Gredos.

Plantan, C. (1996). L'argumentation. Paris: Seuil

Pujante, D. (2011). Teoría del discurso retórico aplicada a los nuevos

lenguajes. El complejo predominio de la elocutio, Rétor, 1 (2), pp. 186-214, 2011

Scott, R., Brand, C. \& Lenz, V. (2001). Marketing emocional. Barcelona: Ed. Gestión.

Sears, D. 0. \& Funk, C. L. (1991). The role of self-interest in social and political attitudes. En M. Zanna (Ed.). Advances in Experimental Social Psychology, Vol. 24. Orlando: Academic Press, pp. 1-91.

Simpson, P. (2001). Reason' and 'tickle' as pragmatic constructs in the discourse of advertising. Journal of Pragmatics, 33, 589-607.

Solana, D. (2010). Postpublicidad. Reflexiones sobre una nueva cultura publicitaria. Barcelona: Doubleyou

Toulmin. S. E. (2007). Los usos de la argumentación, Barcelona: Península (original 1958). 